\title{
Six Education
}

\section{How many ways can you make numbers add up to six? The obvious pairs are $(1,5),(2,4)$, $(3,3),(4,2)$ and $(5,1)$. Ok, I left out $(0,6)$ and $(6,0)$, which are of negligible interest.}

Of course, if you permit negative numbers the number of pairs is infinite: $(-1,7),(-2,8)$, and so on. When I was growing up, we learned our addition and times tables, memorized them, and used that information to do simple arithmetic. I recently had the opportunity to join several thousand teachers in Southern California for an annual confab on teaching. ${ }^{\text {a }}$ came away with a very different view of elementary and secondary education than I had going in.

For years we have tended to measure how well our students have learned by testing what they know. In the discussions at California State University, Fullerton, a different mind set emerged. Why not test what students can do? The shift in focus takes into account that we have myriad ways in the $21^{\text {st }}$ century to find out what we want to know. Part of knowing how to do things is finding information when we need it. Moreover, it seems evident that we learn better not from rote memorization, but from using knowledge to do things. The Montessori schools approach learning from an experiential and exploratory perspective, for example. We learn from our mistakes sometimes more than from our successes. Certainly science tends to work that way.

The Common Core State education standards ${ }^{\mathrm{b}}$ initiative gets at this idea by focusing on the reasons why different

a Better Together: California Teachers Summit 2017 (http://cateacherssummit.com/)

b https://en.wikipedia.org/wiki/Common_Core_ State_Standards_Initiative methods get the same mathematical results. The point is not to use every possible way to do computation but, rather, to understand in a more fundamental way the nature of computation. Students are asked to show their work-their reasoning-as a way of determining how well they have absorbed basic concepts of mathematics, for example. Another way in which this depth of knowledge is assessed is to ask students to show they can make practical estimates of the magnitude of answers they should expect to get. This can be a quick way of ensuring the answers are in the right ballpark. For example:

\section{7 \\ $+332$}

529

To estimate the ballpark, we could sum $200+330$ to get 530 , which is a good approximation to 529 or even $200+300=500$ and easier to do in our heads.

In the No Child Left Behind legislation, testing knowledge was the gold standard but it led to behavior such as "teach to the test." While this might produce good scores, it might not produce good understanding. What I think we want is to produce graduate students who know how to learn and how to find information they need from a variety of sources. This will also prove to be important as children grow into adults and experience longer working careers spanning decades. Without much doubt these adults will need to learn new things to stay current as technology continues its relentless evolutionary pace. Adapting to change will be a career-enhancing capability.

One of the keynote speakers was Jill Biden, a teacher of teachers who, astonishingly, taught at Northern Virginia Community College while serving the U.S. as Second Lady. She referred to the ineffable pain as her stepson, Beau Biden, lost his battle with cancer and drew to mind Vice President Biden's earlier loss of his first wife, Nelia, and daughter, Naomi, in a car crash years before. In her moving account of life before, during, and after the Obama/ Biden Administration she summarized: "What matters most in life is how well we will walk through fire." This, too, was a life lesson I took away from this very thought-provoking event.

In the last couple of months I have also encountered new ways to teach mathematics in online settings. Alexander Khachatryan founded the ReasoningMind organization to create courses in mathematics for pre-K, K, elementary, and secondary school levels. ${ }^{\mathrm{C}}$ I tried some of the lessons for the youngest children and they plainly laid a foundation for understanding the notion of sets and set membership and equivalence classes, all without using unnecessarily complex and obscure terminology.

c https://www.reasoningmind.org/

Vinton G. Cerf is vice president and Chief Internet Evangelist at Google. He served as ACM president from 2012-2014.

Copyright held by author 